\title{
Exosomal microRNAs as diagnostic and therapeutic biomarkers in non-malignant liver diseases
}

\author{
Seonghwan Hwang ${ }^{1}$ Yoon Mee Yang ${ }^{2,3}$ (D)
}

Received: 15 January 2021 / Accepted: 20 June 2021 / Published online: 24 June 2021

(C) The Pharmaceutical Society of Korea 2021

\begin{abstract}
The liver is a vital organ responsible for various physiological functions, such as metabolism, immune response, digestion, and detoxification. Crosstalk between hepatocytes, hepatic macrophages, and hepatic stellate cells is critical for liver pathology. Exosomes are small extracellular vesicles $(50-150 \mathrm{~nm})$ that play an important role in cell-cell or organ-organ communication as they transfer their cargo, such as protein, DNA, and RNA to recipient cells or distant organs. In various liver diseases, the number of liver cell-derived exosomes is increased and the exosomal microRNA (miRNA) profile is altered. Early studies investigated the value of circulating exosomal miRNAs as biomarkers. Several exosomal miRNAs showed excellent diagnostic values, suggesting their potential as diagnostic biomarkers in liver diseases. Exosomal miRNAs have emerged as critical regulators of liver pathology because they control the expression of multiple genes in recipient cells. In this review, we discuss the biology of exosomes and summarize the recent findings of exosome-mediated intercellular and organ-to-organ communication during liver pathology. As there are many review articles dealing with exosomal miRNAs in liver cancer, we focused on non-malignant liver diseases. The therapeutic potential of exosomal miRNAs in liver pathology is also highlighted.
\end{abstract}

Yoon Mee Yang

yym@kangwon.ac.kr

$1 \quad$ College of Pharmacy and Research Institute for Drug Development, Pusan National University, Busan 46241, South Korea

2 Department of Pharmacy, Kangwon National University, Chuncheon-si, Gangwon-do 24341, South Korea

3 KNU Researcher training program for developing Anti-Viral Innovative Drugs, Kangwon National University, Chuncheon 24341, South Korea
Keywords microRNA - Exosomes $\cdot$ Liver diseases · Biomarker

\section{Introduction}

Exosomes are a type of extracellular vesicles (EVs); they are membranous structures originating from different kinds of cells (Szabo and Momen-Heravi 2017). EVs can be classified into microvesicles, apoptotic bodies, and exosomes based on their size, surface proteins, and biogenesis mechanisms (Cocucci and Meldolesi 2015). Exosomes were originally regarded as a remnant of cell degradation to discard unneeded cellular materials (Doyle and Wang 2019); however, they have been increasingly implicated in cellular communication through which cells exchange proteins and genetic material (van Niel et al. 2018). The liver is a complex organ that consists of a number of different types of cells, including parenchymal cells (hepatocytes) and non-parenchymal cells, such as immune cells (e.g., Kupffer cells), liver sinusoidal endothelial cells, hepatic stellate cells, and cholangiocytes (Mehal et al. 2001). Exosomes can be released by most of these liver cells, and thus, may actively participate in intercellular communication not only in the liver but also in the distal organs (Szabo and Momen-Heravi 2017). Exosome-mediated intercellular communication is dependent on the cargo materials present in exosomes, which include proteins and nucleic acids (Fig. 1) such as DNA, mRNA, and microRNA (miRNA; (Turchinovich et al. 2019). Transfer of these materials can alter the activities of recipient cells by regulating gene transcription and expression.

miRNAs are small (20-24 nucleotides in length), noncoding RNAs that mediate post-transcriptional regulation of gene expression (Ha and Kim 2014). They are transcribed as precursor molecules, pri-miRNAs, and subsequently 


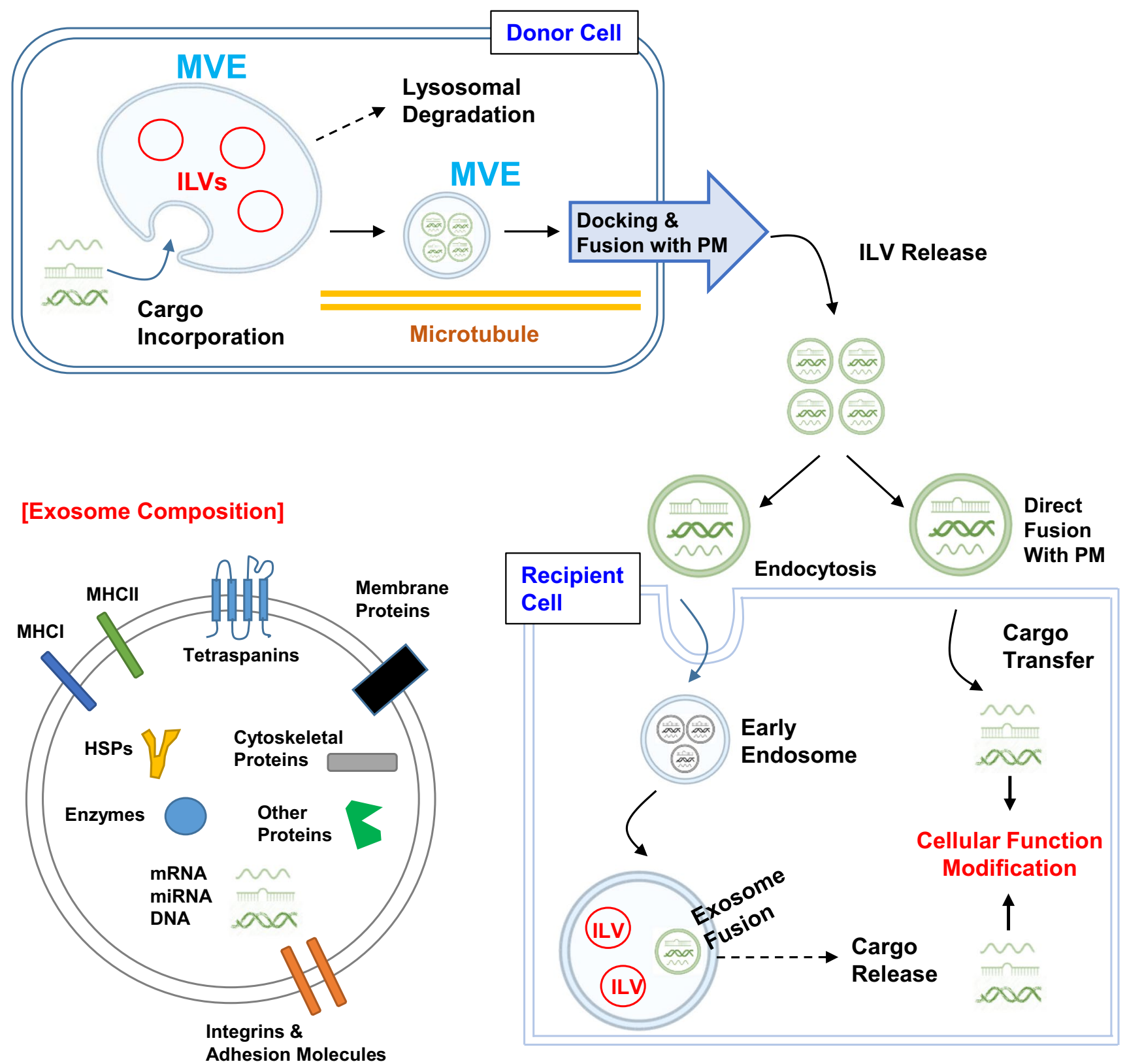

Fig. 1 Exosome biogenesis. Exosomes are composed of diverse materials ranging from nucleic acids to cell surface molecules, heat shock proteins (HSPs), cytoskeletal proteins, and enzymes. Exosomes are generated from the endosomal system by first targeting cargo materials to the limiting membrane of multivesicular endosomes (MVEs), which in turn produces intraluminal vesicles (ILVs). MVEs migrate to the cell surface along microtubules, followed by docking and fusion with the plasma membrane (PM), through which ILVs are released to the extracellular milieu. Released exosomes are internalized into the recipient cell through endocytosis, which produces early endosomes. Exosomes fuse back with the limiting membrane of endosome and release cargoes within the cell to exert a modification of cellular function. Exosomal cargoes can also be transferred to the recipient cells via direct fusion with PM

processed by the RNase III protein Drosha and the endonuclease Dicer to generate mature miRNAs (Treiber et al. 2019). Mature miRNAs form an RNA-induced silencing complex (RISC) in association with argonaute 2 for posttranscriptional regulation (Treiber et al. 2019). As a result, miRNAs bind to specific mRNAs and interfere with translation or reduce the stability of target mRNAs (Heo et al.
2019). The specificity of this reaction and the diversity of the miRNAs incorporated in exosomes have recently highlighted miRNAs as important cargo materials that may explain the molecular pathogenesis of liver diseases (Sato et al. 2016). In this review, we summarize recent advances in our understanding of the roles of exosomal miRNAs in the pathogenesis of liver diseases and their potential as therapeutic targets. 


\section{Exosome biology}

EVs have been recently recognized as intercellular communication mediators. However, it needs to be noted that EV is the term that represents the population of different types of vesicles with profoundly heterogeneous nature, such as exosomes, microvesicles, and apoptotic bodies; thus, it is desirable to understand the specific biology of exosomes that distinguishes them from other subtypes of EVs. Exosomes (50 to $150 \mathrm{~nm}$ in diameter) are smaller than microvesicles (100 to $1000 \mathrm{~nm}$ ) and apoptotic bodies (500 to $2000 \mathrm{~nm}$ ) (Cocucci and Meldolesi 2015). In terms of biogenesis mechanisms, exosomes originate from the endosomal system as intraluminal vesicles (ILVs), and are secreted through the integration of multivesicular endosomes (MVEs) to the cell surface (Fig. 1), whereas microvesicles are formed by direct shedding from the plasma membrane (Raposo and Stoorvogel 2013). Cargoes such as nucleic acids and proteins to be secreted within exosomes are first targeted to the limiting membrane of MVEs, either involving endosomal sorting complexes required for transport (ESCRT) or independently of ESCRT (Zhang et al. 2019). Notably, specific sequence motifs in miRNAs assist in the sorting of miRNAs to exosomes (Villarroya-Beltri et al. 2013). The cargo-containing microdomain structures at the limiting membranes of MVEs are in turn subjected to inward fission to produce ILVs (Möller and Lobb 2020). Afterwards, MVEs migrate to and fuse with the plasma membrane to release ILVs into the extracellular environment (Möller and Lobb 2020).

Although the release of microvesicles is a straightforward event that occurs by pinching off from the plasma membrane, the trafficking and release of exosomes involves multiple steps that can be subjected to regulation at different levels (Hessvik and Llorente 2018). For example, MVEs can fuse with lysosomes resulting in the degradation of MVEs, and with the plasma membrane for the release of ILVs and exosomes (Futter et al. 1996; Treiber et al. 2019). Subsequently, the fate of MVEs is dependent on several factors, including RAB-guanosine triphosphatase (GTPase) RAB7 (Vanlandingham and Ceresa 2009; Guerra and Bucci 2016). Remarkably, RAB7 may promote both targeting to the lysosome and the plasma membrane, which is in part determined by its ubiquitination status. Ubiquitinated RAB7 has been shown to increase the chance of MVEs to be targeted to lysosomes (Song et al. 2016). MVEs that are destined to be released migrate to the plasma membrane along the microtubules. They undergo docking and fusion, two crucial steps for the release of exosomes, and are also regulated by RABGTPases, such as RAB27A, RAB27B, RAB11, and RAB35 (Savina et al. 2002; Hsu et al. 2010; Ostrowski et al. 2010; Blanc and Vidal 2018).

Exosomes released from donor cells bind to recipient cells, possibly altering their cellular function by triggering changes in cellular pathways through interaction with surface receptors and membrane proteins, or by transferring exosome contents into the target cells (van Niel et al. 2018). Exosomes are internalized by multiple endocytosis mechanisms, including macropinocytosis, phagocytosis, clathrin-dependent endocytosis, lipid raft-mediated internalization, and caveolin-mediated uptake, all of which create early endosomes that carry exogenous exosomes to MVEs (Mulcahy et al. 2014). Exosomes that reach MVEs coexist with ILVs until they fuse with the limiting membrane of MVEs (Huotari and Helenius 2011), after which intraluminal materials of exosomes such as miRNA are released into the target cell, thereby triggering changes in cellular function (van Niel et al. 2018). Although endocytosis is considered the major pathway for exosome uptake, exogenous exosomes can also directly fuse with the plasma membrane and release the cargo materials into the target cells to alter cellular function (Fig. 1) (Prada and Meldolesi 2016).

\section{Exosomal miRNAs in liver diseases}

Among a number of cargo materials in exosomes, miRNAs, along with other nucleic acids have been implicated in the pathogenesis of liver diseases (Szabo and Momen-Heravi 2017; Urban et al. 2019). Therefore, exosomal miRNAs have been highlighted as biomarkers for diagnostic and therapeutic purposes in the management of diverse diseases (Sato et al. 2016; Pan et al. 2018). In this section, we discuss the recent literature on the involvement of various exosomal miRNAs in different types of liver diseases (Table 1).

\section{Acute liver injury}

Acute liver injury is one of the major causes of acute liver failure, which is a life-threatening disease in patients without preexisting hepatic disorders (Bernal and Wendon 2013). Emerging evidence has shown that exosomal miRNAs are implicated in the pathogenesis of acute liver injury that is induced by various factors, such as chemical toxicants [e.g., carbon tetrachloride $\left.\left(\mathrm{CCl}_{4}\right)\right]$ and drug overdose. Acute liver injury caused by acetaminophen increased miR-122 levels in the exosome-rich fraction of plasma in mice (Bala et al. 2012). $\mathrm{CCl}_{4}$ administration in mice reduced hepatic levels of miR-208a, and miR-208a-deficient mice were more susceptible to $\mathrm{CCl}_{4}$-induced liver injury associated with enhanced activation of nuclear factor kappa $\mathrm{B}$ and caspase-8-related cellular death pathways (Bala et al. 2020). Plasma exosomal miRNA analysis revealed that exosomal miR-1-3p could be substantially involved in the pathogenesis of anthracyclineinduced liver injury (Zhang et al. 2020c). Expression profiling of exosomal, serum, and hepatic miRNAs identified several exosome-derived miRNAs (e.g., miR-122a-5p) with the potential for use in the diagnosis of acute liver injury 
Table 1 Summary of exosomal micoRNAs and their targets in liver diseases

\begin{tabular}{|c|c|c|c|c|c|}
\hline miRNAs & Expression & Disease model & Exosome source & Targets & References \\
\hline \multicolumn{6}{|c|}{ Acute liver injury } \\
\hline miR-122 & $\uparrow$ & $\begin{array}{l}\text { Acetaminophen, thioaceta- } \\
\text { mide (mouse/rat) }\end{array}$ & Hepatocyte & - & $\begin{array}{l}\text { Bala et al. (2012) and Motawi } \\
\text { et al. (2018) }\end{array}$ \\
\hline miR-208 & $\downarrow$ & $\mathrm{CCl}_{4}$ (mouse) & Hepatocyte & $\mathrm{NF}-\kappa \mathrm{B}$ & Bala et al. (2020) \\
\hline miR-1 & $\uparrow$ & Anthracycline (human) & Hepatocyte & $\begin{array}{l}\text { CXCL1, IGF1, CCL2, ARG1, } \\
\text { IL6, VEGFA, HMOX1 }\end{array}$ & Zhang et al. (2020c) \\
\hline miR-1246 & $\downarrow$ & $\begin{array}{l}\text { Hypoxia-reoxygenation (in } \\
\text { vitro) }\end{array}$ & Hepatocyte & GSK-3 $\beta$ & Xie et al. (2019b) \\
\hline $\operatorname{miR}-20$ & $\downarrow$ & Ischemia-reperfusion (rat) & hUC-MSC & Beclin-1, Fas & Zhang et al. (2020a) \\
\hline $\operatorname{miR}-455$ & $\uparrow$ & IL-6 (in vitro) & hUC-MSC & PIK3R1 & Shao et al. (2020) \\
\hline \multicolumn{6}{|l|}{ NAFLD } \\
\hline miR-192 & $\uparrow$ & $\begin{array}{l}\text { NASH patients (human) } \\
\text { Choline deficient L-amino } \\
\text { acid-defined diet (mouse) }\end{array}$ & Hepatocyte & Rictor & $\begin{array}{l}\text { Liu et al. (2020) and Povero } \\
\text { et al. (2014) }\end{array}$ \\
\hline miR-199 & $\uparrow$ & HFD feeding (mouse) & Hepatocyte & MST1, PPAR- $\alpha$ & Li et al. $2020 \mathrm{~b}$ \\
\hline miR-122 & $\uparrow$ & $\begin{array}{l}\text { Cholesterol (in vitro) } \\
\text { Choline deficient L-amino } \\
\text { acid-defined diet (mouse) } \\
\text { MCD diet feeding (mouse) }\end{array}$ & Hepatocyte & $\begin{array}{l}\text { HIF-1 } \alpha, \text { Vimentin, MAP3K3, } \\
\text { HO-1 }\end{array}$ & $\begin{array}{l}\text { Csak et al. (2015), Povero et al. } \\
\text { (2014) and Zhao et al. (2020b) }\end{array}$ \\
\hline $\operatorname{miR}-155$ & $\uparrow$ & HFD feeding (mouse) & Adipose tissue macrophage & PPAR- $\gamma$ & Ying et al. (2017) \\
\hline miR-223 & $\uparrow$ & HFD feeding (mouse) & Myeloid cell & TAZ, CXCL1, NLRP3 & $\begin{array}{l}\text { He et al. (2020) and Hou et al. } \\
(2020)\end{array}$ \\
\hline \multicolumn{6}{|c|}{ Alcoholic liver disease } \\
\hline miR-155 & $\uparrow$ & $\begin{array}{l}\text { Alcoholic hepatitis (human), } \\
\text { Lieber-DeCarli diet for } \\
5 \text { weeks (mouse) }\end{array}$ & Liver, hepatocyte, Kupffer cell & $\begin{array}{l}\text { SOCS1, mTOR, Rheb, } \\
\text { LAMP1, LAMP2 }\end{array}$ & $\begin{array}{l}\text { Momen-Heravi et al. (2014) and } \\
\text { Babuta et al. (2019) }\end{array}$ \\
\hline miR-122 & $\uparrow$ & $\begin{array}{l}\text { Binge alcohol drinking } \\
\text { (human and mouse), } \\
\text { Lieber-DeCarli diet for } \\
5 \text { weeks (mouse) }\end{array}$ & Hepatocyte & HO-1 & Momen-Heravi et al. (2015a) \\
\hline $\operatorname{miR}-27 a$ & $\uparrow$ & Alcoholic hepatitis (human) & Monocyte & Increase of CD206 & Saha et al. (2016) \\
\hline \multicolumn{6}{|l|}{ Viral hepatitis } \\
\hline $\operatorname{miR}-29$ & $\uparrow$ & $\mathrm{HCV}$ infection (in vitro) & Macrophage & $\begin{array}{l}\text { HCV genome targeting } \\
\text { Activate cellular anti-HCV } \\
\text { response }\end{array}$ & Zhou et al. (2016) \\
\hline HBV-miR-3 & $\uparrow$ & $\begin{array}{l}\text { HBV transfection/infection } \\
\text { (in vitro) }\end{array}$ & $\begin{array}{l}\text { Hepatoma cell lines with an } \\
\text { integrated HBV genome }\end{array}$ & $\begin{array}{l}\text { SOCS5, HBV } 3.5-\mathrm{kb} \text { mRNA } \\
\text { encoding HBV core protein }\end{array}$ & $\begin{array}{l}\text { Yang et al. (2017b) and Zhao } \\
\text { et al. (2020a) }\end{array}$ \\
\hline \multicolumn{6}{|l|}{ Liver fibrosis } \\
\hline $\operatorname{miR}-214$ & $\downarrow$ & $\begin{array}{l}\mathrm{CCl}_{4} \text {-induced liver fibrosis } \\
\text { (mouse) }\end{array}$ & Hepatic stellate cell & $\mathrm{CCN} 2$ & Chen et al. (2014) \\
\hline miR-199a-5p & $\downarrow$ & $\begin{array}{l}\text { Quiescent and activated pri- } \\
\text { mary mouse hepatic stellate } \\
\text { cells (in vitro) }\end{array}$ & Hepatic stellate cell & $\mathrm{CCN} 2$ & Chen et al. (2016) \\
\hline miR-30a & $\downarrow$ & $\begin{array}{l}\text { TGF- } \beta 1 \text {-treated LX-2 cells } \\
\text { (in vitro) }\end{array}$ & Hepatic stellate cell & Beclin1 & Chen et al. (2017) \\
\hline $\begin{array}{l}\text { miR-19b } \\
\text { miR-92 }\end{array}$ & $\uparrow$ & $\begin{array}{l}\text { Lieber-DeCarli diet + LPS } \\
\quad \text { (rat) }\end{array}$ & Hepatic stellate cell & $\begin{array}{l}\text { TGF-RII, MeCP2 } \\
\text { SMAD7 }\end{array}$ & Brandon-Warner et al. (2016) \\
\hline $\begin{array}{l}\operatorname{miR}-17 \mathrm{a} \\
\mathrm{miR}-18 \mathrm{a}\end{array}$ & $\downarrow$ & $\begin{array}{l}\text { Lieber-DeCarli diet + LPS } \\
\quad \text { (rat) }\end{array}$ & Hepatic stellate cell & $\begin{array}{l}\text { P21, BCL2L11, SMAD7 } \\
\text { CTGF, TSP-1 }\end{array}$ & Brandon-Warner et al. (2016) \\
\hline miR-19a & $\uparrow$ & $\begin{array}{l}\text { HCV-infected hepatocyte (in } \\
\text { vitro) }\end{array}$ & HCV-infected hepatocyte & SOCS3 & Devhare et al. (2017) \\
\hline
\end{tabular}

$N A S H$ nonalcoholic steatohepatitis, $H F D$ high-fat diet, $M C D$ methionine-choline-deficient, $H C V$ hepatitis $\mathrm{C}$ virus, $H B V$ hepatitis $\mathrm{B}$ virus, $L P S$ lipopolysaccharide

induced by drugs (e.g., acetaminophen and thioacetamide) (Motawi et al. 2018). Idiosyncratic drug-induced liver injury (IDILI) is an acute liver injury caused by drugs only in a certain type of individuals (Teschke 2019). The specificity of IDILI is highly associated with human leukemia antigen serotypes in patients, and thus, its pathogenesis is thought to be attributable to the adaptive immune system (Yamashita et al. 2017; Uetrecht 2019). A recent study determined 
the immunoregulatory potential of exosomal miRNAs and their implications for IDILI (Holman et al. 2019). Treatment with hepatocyte-derived exosomes (HDEs) attenuated the lipopolysaccharide (LPS)-induced immune response in THP-1 cells with reduced expression of interleukin (IL)-1 $\beta$, IL-8, and tumor necrosis factor (TNF)- $\alpha$ (Holman et al. 2019). These downregulated genes were predicted to be targeted by miRNAs enriched in HDEs.

Mesenchymal stem cells (MSCs) are multipotent stem cells that can differentiate into mesodermal, ectodermal, and endodermal lineages (Ullah et al. 2015). MSCs have been recently reported to have therapeutic potential in various diseases as they modulate immune reactions and promote cell regeneration (Parekkadan and Milwid 2010; Wang et al. 2018). Several recent studies have elucidated the immunosuppressive effects of MSCs in the liver. For example, exosomes isolated from the supernatant of mouse bone marrow-derived MSCs attenuated concanavalin A-induced $\mathrm{T}$ cell-mediated liver injury in mice (Tamura et al. 2016). Exosomal miRNAs have also emerged as potential mediators of the therapeutic benefit of MSCs. Miyaji et al. reported that miRNAs derived from bone marrow cells such as miR-92b-3p, miR-23b-3p, miR-204-3p, miR-1247-3p, and miR-326-5p improved the effectiveness of MSC therapy by upregulating TNF-stimulated gene 6 and/or repressing mitochondrial oxidative phosphorylation in vitro and in a $\mathrm{CCl}_{4}$-induced liver injury model (Miyaji et al. 2020). IL-6 mediates the acute phase response to normalize hepatic function after liver injury (Schmidt-Arras and Rose-John 2016); however, it can also induce a cytokine storm and liver injury (Kong et al. 2016). Shao et al. reported that IL-6 treatment enhanced exosome secretion from human umbilical cord-derived MSCs (hUC-MSCs), and these exosomes repressed LPS-induced macrophage activation (Shao et al. 2020). Among the miRNAs that may regulate IL-6 signaling, miR-455-3p was one of the most highly upregulated upon IL-6 treatment, and it repressed LPS-induced hepatic macrophage activation in mice through regulation of PI3kinase regulatory subunit 1 (Shao et al. 2020).

Ischemia/reperfusion injury is a common cause of acute liver failure after liver transplantation and resection (Weigand et al. 2012), and the protective effect of MSCs in ischemia/reperfusion injury has been increasingly explored. LO2 human liver cell line subjected to hypoxia/ reoxygenation underwent cell death and downregulated miR1246 expression (Xie et al. 2019b). Treatment with hUCMSC-derived exosomes upregulated miR-1246, induced anti-apoptotic genes in LO2 cells, and improved ischemia/ reperfusion-induced liver dysfunction in mice via the glycogen synthase kinase- $3 \beta$-Wnt/ $\beta$-catenin pathway (Xie et al. $2019 b)$. Another study from the same group reported that miR-1246 in hUC-MSC-derived exosomes ameliorated ischemia/reperfusion injury in mice by decreasing the Th17/
Treg ratio in $\mathrm{CD}^{+} \mathrm{T}$ cells via a mechanism involving the IL-6-gp130-signal transducer and activator of transcription (STAT) 3 pathway (Xie et al. 2019a). miR-20a also mediates the protective effect of MSCs against ischemia/reperfusion injury by inhibiting the expression of Beclin- 1 and Fas, the regulators of autophagy and apoptosis, respectively (Zhang et al. 2020a).

The combination of LPS and D-galactosamine (D-GalN) is widely used to induce acute liver failure in animals (Josephs et al. 2000). TNF-treated hUC-MSCs ameliorated LPS + D-GalN-induced acute liver failure in mice by suppressing the macrophage NLRP3 inflammasome. An antiinflammatory miR-299-3p, whose levels were elevated in exosomes derived from TNF-treated hUC-MSCs, had potential involvement in this process (Zhang et al. 2020b). Another study reported that exosomes obtained from adipose tissue-derived mesenchymal MSCs ameliorated LPS + D-GalN-induced acute liver failure, which occurred through miR-17-dependent inhibition of thioredoxin-interacting protein and inflammasome activity (Liu et al. 2018b).

\section{Nonalcoholic fatty liver disease (NAFLD)}

Recently, there has been an increase in the incidence of metabolic diseases, including a hepatic manifestation of these diseases known as NAFLD. Its major risk factors include obesity and diabetes (Friedman et al. 2018; Lee et al. 2019). NAFLD ranges from fatty liver to nonalcoholic steatohepatitis, cirrhosis, and hepatocellular carcinoma (HCC), and is highly associated with the dysregulated expression of genes involved in hepatic metabolism of lipids and energy (Gjorgjieva et al. 2019). Given the ability of miRNAs to regulate various gene expression, they have been investigated as potential regulators of the pathogenic mechanisms of NAFLD, and several miRNAs (e.g., miR-34a, miR-122, and miR-192) have been suggested as biomarkers for NAFLD (Liu et al. 2018a). In mice, levels of NAFLD-associated miRNAs such as miR-122 and miR-192 were substantially elevated in circulating EVs after 20 weeks of feeding choline-deficient $\mathrm{L}$-amino acid-defined diet, which causes severe steatosis and inflammation in the liver (Povero et al. 2014; Yang et al. 2017a). miR-199a-5p was highly upregulated in the steatotic liver of mice on a high-fat diet (HFD; Li et al. 2020b). Exosome-associated delivery of miR-199a-5p in mice promoted hepatocyte fat accumulation by downregulation of macrophage stimulating 1 and modulation of genes involved in fatty acid metabolism ( $\mathrm{Li}$ et al. 2020b).

The additional role of exosomal miRNAs in the progression of steatosis to nonalcoholic steatohepatitis (NASH) has also been investigated. Feeding mice a methionine-cholinedeficient diet caused NASH-related fibrosis and increased serum exosomal miR-122 levels while reducing hepatic miR122 levels (Csak et al. 2015). A decrease in hepatic miR-122 
activated hypoxia-inducible factor (HIF)- $1 \alpha$, vimentin, and mitogen-activated protein kinase kinase kinase 3 , which are regulated by miR-122, thereby promoting fibrosis (Csak et al. 2015). Cholesterol has emerged as a crucial inducer of liver injury and inflammation that contributes to NASH development (Ioannou 2016). Cholesterol increased the release of miR-122-5p-enriched exosomes from Huh7 hepatoma cells, and treatment of THP-1 macrophages with these exosomes promoted M1 polarization in an miR-122-5p-dependent manner (Zhao et al. 2020b). Serum miR-192-5p levels were also correlated with the severity of NAFLD in human patients, and exosomal miR-192-5p derived from lipotoxic hepatocytes activated M1 macrophages by targeting Rictor, which suppressed the phosphorylation of protein kinase B (Akt) and forkhead box protein O1 (FOXO1). This in turn triggered the FOXO1-mediated inflammatory response (Liu et al. 2020).

Besides the hepatocyte-released miRNAs mentioned above, exosomal miRNAs released by myeloid cells have also attracted attention as mediators of NAFLD development. miR-223 is predominantly expressed in myeloid cells and participates in inflammation regulation (Ye et al. 2018), but can also be transferred to other liver cell types (e.g., hepatocytes) via exosomes (He et al. 2020). Myeloid-specific deletion of the Il6ra gene in mice accelerated HFD-induced fibrosis development by lowering miR-223 levels in hepatocytes and subsequently activating fibrogenic mediators, such as transcriptional activator with PDZ-binding motif (TAZ) (Hou et al. 2020).

\section{Alcoholic liver disease}

Alcohol consumption was the 7th leading risk factor for death and disability-adjusted life-years in 2016 (Collaborators GBDA 2018). Moreover, excessive alcohol intake causes alcoholic liver disease, which is one of the most common causes of cirrhosis (Collaborators GBDC 2020). More than $90 \%$ of heavy drinkers develop alcoholic fatty liver, and a certain population of patients can progress to alcoholic hepatitis (Basra and Anand 2011).

The total number of circulating EVs/exosomes was elevated in patients with alcoholic hepatitis compared with healthy individuals (Momen-Heravi et al. 2015b). Similarly, chronic alcohol feeding [5\% (v/v) ethanol containing Lieber-DeCarli diet for 4 weeks] increased the number of EVs in mice sera. Chronic alcohol consumption increased miR-155 levels in mouse livers, hepatocytes, and Kupffer cells isolated from alcohol-fed mice compared to the miRNA levels in the control mice (Babuta et al. 2019). Increased miR-155 by ethanol decreased lysosomal-associated membrane protein 1 (LAMP1) and LAMP2 levels, which regulate the fate of multivesicular bodies and exosome biogenesis. miR-155 deficiency or inhibition of LAMP1 and LAMP2 reduced alcohol-induced exosome production in hepatocytes and Kupffer cells (Babuta et al. 2019). Exosome-mediated delivery of a functionally active miR-155 inhibitor was investigated (Momen-Heravi et al. 2014). The delivery of the miR-155 inhibitor was effectively achieved using B cell-derived exosomes. This approach led to reduced LPSinduced TNF $\alpha$ production in macrophages and increased mRNA expression of suppressor of cytokine signaling (SOCS) 1 protein, a miR-155 target gene (Momen-Heravi et al. 2014). Exosome-based miRNA inhibitor delivery may be beneficial for the regulation of exosome production as well as for the modification of miR-155 target genes.

Increased miRNA signatures of EVs derived from sera of chronic alcohol-fed mice were identified: miR-122, miR-192, miR-30a/b, miR-1246, miR-130a, and miR-744 (Momen-Heravi et al. 2015b). miR-122 and miR-192 are major liver-enriched miRNAs (Yang et al. 2015). miR-192 showed excellent diagnostic value in both mice and humans (Momen-Heravi et al. 2015b); therefore, it can be a potential diagnostic biomarker for alcoholic liver disease.

miR-122 is the most abundant miRNA in the liver (Yang et al. 2012). Circulating miR-122 in exosomes is a good indicator of hepatocyte injury and inflammation. Serum miR-122 levels were elevated not only in alcoholic liver disease, but also in drug-induced liver injury and inflammatory liver diseases (Bala et al. 2012). Serum miR-122 levels and alanine aminotransferase levels were positively correlated in alcoholic liver disease. Toll-like receptor (TLR) 4 signaling or oxidative stress regulate serum miR-122 levels in ethanol-fed mice (Bala et al. 2012). Endoplasmic reticulum stress also contributes to ethanol-induced exosomal miR-122 and acute liver injury (Wang et al. 2019). Ethanol-treated hepatocytes secrete exosomes containing miR-122, which is horizontally transferred to monocytes (Momen-Heravi et al. 2015a). Exosomal miR-122 recipient monocytes inhibited the HO-1 pathway, sensitization to LPS stimulation, and induction of pro-inflammatory cytokine production (Momen-Heravi et al. 2015a). Increased exosomal miR-122 by ethanol mediates intracellular communication between hepatocytes and monocytes.

The Szabo group investigated the miRNA cargo of EVs from alcohol-exposed monocytes. Ethanol treatment increased the number of EVs in monocytes. miR-27a levels were increased in plasma EVs of patients with alcoholic hepatitis. EVs isolated from ethanol-treated monocytes contained higher levels of miR-27a compared to those from vehicle-treated cells (Saha et al. 2016). miR-27a-loaded EVs stimulate naïve monocytes to differentiate into macrophages and promote anti-inflammatory cytokine production and phagocytosis (Saha et al. 2016). Monocyte-derived extracellular vesicular miR-27a can affect monocyte phenotypes and macrophage polarization even when neighboring EV recipient cells are not directly stimulated by ethanol. 
These findings suggest that alcoholic liver disease promotes the total number of exosomes containing specific miRNA cargoes, which contributes to exosome biogenesis and pathophysiological processes, such as cytokine production. Exosomal miRNAs, especially miR-192, could be used as a potential diagnostic marker for alcoholic liver disease.

\section{Viral hepatitis}

In response to a hepatitis $\mathrm{B}$ or $\mathrm{C}$ infection, the host innate immunity acts as a first line defense to eliminate the virus. To overcome the evasion of host innate immunity by viruses, understanding of intercellular communications between hepatocytes and immune cells is important.

Liver macrophages are activated by TLRs in response to phagocytosed viral DNAs and/or RNAs released from hepatitis C virus (HCV)-infected hepatocytes (Heydtmann 2009). TLR3-activated macrophages produce exosomal anti-viral miRNAs, such as miR-29 family members. Exosomes are taken up by hepatocytes, where anti-viral miRNAs induce an anti-HCV response or directly target HCV gene expression (Zhou et al. 2016).

Hepatitis B surface antigen particles can carry miRNAs, especially pools of $\mathrm{HCC}$, and they are released into the circulation within exosomes or microvesicles (Novellino et al. 2012). In patients with a hepatitis B virus (HBV) infection, HBV-encoded miRNA (called HBV-miR-3) is secreted into the bloodstream by exosomes and HBV virions (Yang et al. 2017b). HBV-miR-3 inhibits HBV replication and protein production (Yang et al. 2017b). HBV-miR-3 targets SOCS5 expression, leading to an interferon- $\alpha$-induced anti-HBV effect, as mediated by the Janus kinase (JAK)/STAT pathway in hepatocytes. In addition, inhibition of SOCS5 by exosomal HBV-miR-3 facilitated M1 macrophage polarization and stimulated IL-6 secretion (Zhao et al. 2020a). Taken together, HBV-miR-3 directly restrained HBV replication, whereas it enhanced the host innate immune response.

\section{Liver fibrosis}

NAFLD, alcoholic liver disease, viral hepatitis, and drug- or toxicant-induced liver injury can cause liver fibrosis. Liver fibrosis is characterized by excessive extracellular matrix (ECM) deposition (Yang et al. 2019, 2021). Hepatic stellate cells (HSCs) are the major players in the fibrosis process. They are activated during liver fibrogenesis. Activated HSCs acquire proliferative, migratory, and fibrogenic phenotypes (Bataller and Brenner 2005).

Connective tissue growth factor (CCN2), a profibrogenic inducer, activates HSCs and the progression of liver fibrosis (Rachfal and Brigstock 2003). CCN2 promotes HSC proliferation and ECM production. The Brigstock group showed the regulation of CCN2 by exosomal miRNAs. Exosomal
miR-214 derived from HSCs mediated HSC-HSC intercellular signaling by epigenetic regulation of CCN2 (Chen et al. 2014). The following studies from the same group demonstrated that endogenous or exosomal components of the Twist1-miR-199a-5p/miR-214 axis regulated CCN2 in HSCs (Chen et al. 2015, 2016). In quiescent HSCs, miR-199a-5p and miR-214 were highly expressed by the regulation of the Twist1 transcription factor. High levels of exosomal miR199a-5p and miR-214 suppressed CCN2 expression. In activated HSCs, Twist1, miR-199a-5p, and miR-214 levels were low, and therefore, the deposition of collagen $1 \alpha$ was increased in association with higher expression of CCN2 (Chen et al. 2015, 2016). The activated HSC phenotype can be reversed by the uptake of exosomes from quiescent HSCs.

In patients with NAFLD, liver fibrosis was associated with liver-related morbidity (Taylor et al. 2020). Treatment with palmitic acid stimulated exosome production in hepatocytes (Lee et al. 2017). The exosomal miRNA profile was altered by palmitic acid. In particular, miR-122, miR-192 miR-24, miR-19b, and miR-34a were greatly increased in exosomes from palmitic acid-treated Huh7 cells. Exosomes derived from palmitic acid-treated hepatocytes showed increased fibrotic gene expression in HSCs (Lee et al. 2017). Serum miR-122 levels increased, whereas hepatic miR-122 levels decreased (Csak et al. 2015). Decreased hepatic miR122 was responsible for the induction of miR-122 targets, HIF- $1 \alpha$ and vimentin in hepatocytes. HIF- $1 \alpha$ overexpression was correlated with liver fibrosis (Csak et al. 2015). MSC transplantation can be considered as a potential therapeutic strategy in treating liver fibrosis. miR-122-modified adipose tissue-derived MSCs efficiently packaged miR-122 into exosomes (Lou et al. 2017). This approach exhibited an anti-fibrotic effect (Lou et al. 2017).

Lipid overload modulates autophagy, an intracellular pathway that mediates the breakdown of lipid droplets. Lipids including retinyl esters, triglycerides, cholesteryl esters, cholesterol, phospholipids, and free fatty acids are present in quiescent HSCs (Blaner et al. 2009). Increased autophagic flux causes loss of lipid droplets and HSC activation (Kim et al. 2018). miR-30a was under-expressed in exosomes of transforming growth factor (TGF)- $\beta 1$-treated LX-2 cells (a human HSC cell line) (Chen et al. 2017). miR-30a downregulated the expression of Beclin-1, which ameliorates autophagy and HSC activation (Chen et al. 2017). Exosomal miRNAs can modulate central players in autophagy (i.e., Beclin-1) under fibrotic stimuli.

Excessive alcohol consumption is one of the major risk factors for liver fibrosis. The association between the miR17/92 cluster and alcoholic liver fibrosis has been investigated. The miR-17/92 cluster has various roles in many pathological situations, such as liver, immune, and cardiovascular diseases, neurological disorders, and cancers (Mogilyansky and Rigoutsos 2013). The miR-17/92 cluster 
consists of miR-17, miR-18a, miR-19a, miR-20a, miR19b-1, and miR-92a-1. The expression profile of the miR17/92 cluster in exosomes has been proposed as a non-invasive diagnostic marker for several cancers (Komatsu et al. 2014). Previously, Koo et al. demonstrated that dysregulation of miR-18a, is responsible for upregulating SMAD2 protein in HSCs, and thereby, promoting liver fibrosis under ER stress conditions (Koo et al. 2016). The expression of other miR-17/92 cluster members (miR-19b and miR-92) was downregulated in activated HSCs, but was upregulated in HSC exosomes (Brandon-Warner et al. 2016). In addition, miR-19b and miR-92 levels were increased in exosomes isolated from the sera of rats fed the Lieber-DeCarli diet with biweekly intraperitoneal LPS injections compared to the pair-fed control diet. Consistently, exosomes isolated from plasma samples of patients with alcoholic liver cirrhosis or alcoholic liver cirrhosis associated with HCC had higher expression of miR-19b and miR-92 compared to healthy controls (Brandon-Warner et al. 2016). This suggests that exosomal miR-19b and miR-92 can serve as novel biomarkers for alcoholic cirrhosis.

HCV infection is another major risk factor for liver fibrosis progression. However, the underlying mechanisms are poorly understood. Two groups showed that intercellular communication between $\mathrm{HCV}$-infected hepatocytes and HSCs through exosomal transmission of miRNAs can contribute to $\mathrm{HCV}$-mediated liver fibrosis. Exosomes derived from $\mathrm{HCV}$-infected hepatocytes were internalized into HSCs and increased profibrogenic gene expression (Devhare et al. 2017). miR-19a is highly expressed in the exosomes derived from $\mathrm{HCV}$-infected hepatocytes as well as in the sera of HCV-infected patients with liver fibrosis. As miR-19a targets SOCS3, exosomes derived from HCV-infected hepatocytes and miR-19a activated the STAT3/TGF- $\beta$ signaling axis (Devhare et al. 2017). Exosomal miR-192 was derived from $\mathrm{HCV}$-infected hepatocytes and delivered to HSCs. Exosomal miR-192 also promoted the activation and transdifferentiation of HSCs into myofibroblasts (Kim et al. 2019). These results suggest that miR-19a and miR-192 can be diagnostic and therapeutic targets for HCV-mediated liver fibrosis.

The therapeutic value of EVs for liver fibrosis treatment was explored. Administration of EVs from normal mice ameliorated $\mathrm{CCl}_{4}$ - or thioacetic acid-induced liver fibrosis (Chen et al. 2018). EVs from normal mice contain higher expression of miR-34c, miR-151-3p, miR-483-5p, miR532-5p, and miR-687, as compared to EVs from fibrotic mice. These miRNAs individually suppress the fibrotic response in HSCs and hepatocyte proliferation (Chen et al. 2018). In conclusion, EVs from healthy subjects may be a potential strategy to treat liver fibrosis.

The potential use of exosomal microRNAs as biomarkers for liver fibrosis has been investigated. The levels of exosomal miR-16 were decreased in patients with liver cirrhosis, and downregulation of exosomal miR-16 was associated with poor overall survival of these patients (Fründt et al. 2021). Moreover, exosomal miR-155 levels gradually increased with the degree of liver fibrosis (Niu et al. 2021). Increased exosomal miR-155 positively correlated with the progression of cirrhosis in patients, suggesting that it can be used as a biomarker for liver fibrosis diagnosis and progression. In addition, serum exosomal miR-103-3p levels were also overexpressed in patients with liver fibrosis (Chen et al. 2020). Furthermore, in the advanced stage of liver fibrosis, the levels of exosomal miR-103-3p were increased. Schistosomiasis, an infection caused by Schistosoma mansoni and $S$. japonicum, can lead to the development of periportal fibrosis and liver cirrhosis (Cai et al. 2020). Serum exosomal miR-146a-5p has the potential to serve as a biomarker for grading liver fibrosis due to schistosomiasis (Cai et al. 2020). Furthermore, exosomal microRNA biomarkers that enable us to predict the effects of prognostic anti-fibrotic treatments, such as the phosphodiesterase 5 inhibitor were identified in vivo; these included exosomal miR-99b, miR100, and miR-142-3p (Broermann et al. 2020). Their clinical implications should be further evaluated. In summary, exosomal microRNAs could potentially be used as diagnostic, prognostic, and/or surrogate biomarkers for liver fibrosis.

\section{Inter-organ crosstalk between liver and adipose tissue in the regulation of glucose and lipid metabolism}

Exosomes mediate intercellular communication. They deliver bioactive cargoes to target cells and have autocrine and paracrine actions. Moreover, exosomes are important conduits for inter-organ communication. The liver is a vital metabolic organ that governs systemic glucose and lipid homeostasis. Here, we will discuss the roles of exosomes in crosstalk between the liver and other metabolic organs (Fig. 2).

Obesity is associated with insulin resistance and NAFLD. Obesity-associated exosomal miRNAs, miR-122, miR-192, miR-27a-3p, and miR-27b-3p, are liver abundant miRNAs with increased expression in obesity (Castano et al. 2018). Lean mice treated with exosomes isolated from obese mice developed glucose intolerance and insulin resistance. Administration of exosomes transfected with obesity-associated exosomal miRNAs downregulated the expression of Ppara in white adipose tissue (WAT) and resulted in dyslipidemia. Obesity-associated exosomal miRNAs contribute to glucose intolerance, insulin resistance, as well as epididymal WAT inflammation and hepatic steatosis (Castano et al. 2018). A study by Castano et al. showed that miR-122 and miR-192 expression was decreased in WAT but increased in the liver. However, there is no direct evidence of the source of obesity-associated exosomal miRNAs (Castano et al. 2018). Wu et al. investigated the role of exosomes 


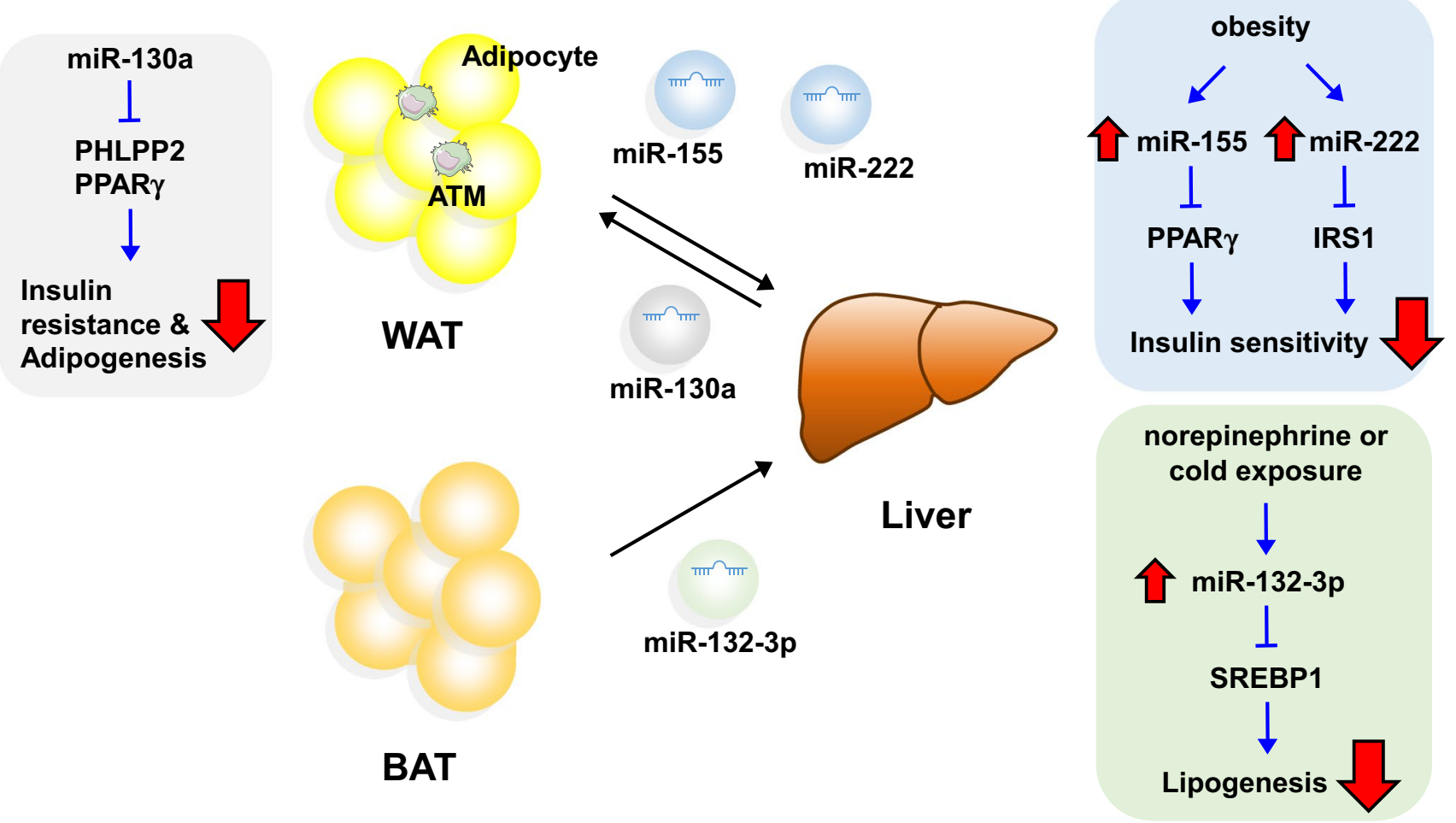

Fig. 2 Role of exosomal miRNAs in crosstalk between liver and fat in the regulation of glucose and lipid metabolism. The liver secretes exosomes containing miR-130a-3p, which target PHLPP2 and PPAR $\gamma$ in adipocytes. Downregulation of PHLPP2 and PPAR $\gamma$ by miR-130a-3p results in the inhibition of glucose intolerance and adipogenesis, respectively. Brown adipocytes produce exosomes carrying miR-132-3p. Brown adipocyte-derived miR-132-3p downregulates Srebfl (encoding a SREBP1 precursor protein) in the liver, leading to suppression of lipogenic gene expression. In the obese state, adipose tissue macrophage-derived miR-155 targets PPAR $\gamma$ in the liver. Obese gonadal white adipose tissuederived miR-222 targets hepatic IRS1. Exosomal miR-155 and exosomal miR-222 contribute to glucose intolerance and insulin resistance. ATM adipose tissue macrophage, BAT brown adipose tissue, IRS1 insulin receptor substrate 1, PHLPP2 PH domain leucine-rich repeat-containing protein phosphatase 2, PPAR $\gamma$ peroxisome proliferator-activated receptor $\gamma, S R E B P 1$ sterol regulatory element-binding protein 1 , WAT white adipose tissue

derived from the liver in liver-fat crosstalk. Hepatic exosome-derived miR-130a-3p improved glucose intolerance by targeting the $\mathrm{PH}$ domain leucine-rich repeat-containing protein phosphatase 2 (PHLPP2). PHLPP2 dephosphorylates Akt. Therefore, hepatic exosome-derived miR-130a-3p activated Akt/glucose transporter type 4 signaling in adipocytes (Wu et al. 2020). Hepatic exosome-derived miR130a-3p also suppressed peroxisome proliferator-activated receptor (PPAR)- $\gamma$ in adipocytes, which in turn attenuated adipogenesis (Wu et al. 2020). Thus, exosomal miRNAs produced by the liver can regulate glucose and lipid metabolism via liver-fat communication.

Adipose tissue is a key organ for energy storage. Adipocytes regulate whole-body energy metabolism via the production of adipokines. Adipose tissue also secretes exosomes and communicates with distant organs, including the liver. Humans with lipodystrophy exhibited a decrease in circulating exosomal miRNAs (Thomou et al. 2017). Adipose-tissue-specific knockout of the miRNA-processing enzyme Dicer (ADicerKO) in mice exhibited lipodystrophy and insulin resistance, and these mice showed higher expression of fibroblast growth factor (FGF) 21. The Kahn group showed that fat tissue is a primary source of exosomal miRNAs in ADicerKO mice (Thomou et al. 2017).

Fat transplantation reconstituted circulating exosomal miRNA profiling. Transplantation of subcutaneous inguinal WAT, intraabdominal epididymal WAT, and brown adipose tissue (BAT) from wild-type donor mice to ADicerKO mice showed distinct circulating exosomal miRNA signatures. Fat-derived exosomal miRNAs play an important role in regulating glucose and lipid metabolism through fat-to-liver communication. ADicerKO mice that received transplantation of fat, especially BAT, exhibited substantially improved insulin sensitivity. Fat-derived exosomal miR-99b is responsible for the robust inhibition of FGF21 in the liver (Thomou et al. 2017). Brown adipocyte-derived exosomal miR-132-3p targets Srebfl in the liver, which is the major regulator of lipid homeostasis (Kariba et al. 2020).

Obese adipose tissue-derived exosomal miRNAs may promote systemic insulin resistance. In the sera from 
patients with type 2 diabetes, exosomal miR-222 was mainly produced by gonadal WAT (Li et al. 2020a). Gonadal WAT-derived exosomal miR-222 downregulated insulin receptor substrate-1 (IRS1), which resulted in insulin resistance in the liver and skeletal muscle of HFD-fed obese mice ( $\mathrm{Li}$ et al. 2020a). In addition to adipocytes, adipose tissue macrophages (ATMs) secrete exosomes. Treatment of lean mice with obese ATM exosomes promoted insulin resistance in the liver, skeletal muscle, and visceral adipose tissues, whereas treatment of obese mice with lean ATM exosomes attenuated insulin resistance (Ying et al. 2017). One of the cargoes overexpressed in ATM-derived exosomes is miR-155, which represses PPAR $\gamma$ expression and impairs cellular insulin signaling. ATM-derived exosomal miR-155 promoted obesity-induced insulin resistance conferred by other obese ATM-exosomes (Ying et al. 2017). These studies suggest that exosomal miRNAs produced by the adipose tissue compartment can influence metabolic events in distant tissues, such as the liver and skeletal muscles.

\section{Conclusions and perspectives}

Given that multiple types of liver cells release miRNAs within exosomes, which may represent the physiological and pathological status of the liver, exosomal miRNAs have been actively investigated as biomarkers of various liver diseases. Emerging studies have also established the critical role of exosomal miRNAs in communication between different cells as well as in different organs, which may further provide mechanistic evidence for the pathogenic properties of exosomes. Recently, the safety of exosomes in patients and the therapeutic effect of exosomes have been evaluated in various diseases, such as COVID-19, type I diabetes mellitus, and cutaneous wound healing have been evaluated in clinical trials (www.clinicaltrials.gov/). Although clinical evidence supporting the feasibility of miRNA therapy in liver diseases is still lacking, the potential benefit of exosome therapy has been demonstrated at the animal level in experimental models of various liver diseases, which has established an empirical foundation for its clinical application. Continuous efforts to reveal the biological and pathological knowledge of miRNAs at the bench- and bedside will open new avenues for the discovery of potential therapeutic options for the treatment of liver diseases.

Acknowledgements This work was supported by the National Research Foundation of Korea (NRF) Grant funded by the Korea Government (MSIT) (Nos. 2021R1A4A3031661 and 2020R1C1C1004185).

\section{Declarations}

Conflict of interest The authors declare that they have no conflict of interest to declare.

\section{References}

Babuta M, Furi I, Bala S, Bukong TN, Lowe P, Catalano D, Calenda C, Kodys K, Szabo G (2019) Dysregulated autophagy and lysosome function are linked to exosome production by micro-RNA 155 in alcoholic liver disease. Hepatology 70:2123-2141. https://doi. org/10.1002/hep.30766

Bala S, Calenda CD, Catalano D, Babuta M, Kodys K, Nasser IA, Vidal B, Szabo G (2020) Deficiency of miR-208a exacerbates $\mathrm{CCl}_{(4)}$-induced acute liver injury in mice by activating cell death pathways. Hepatol Commun 4:1487-1501. https://doi.org/10. 1002/hep4.1540

Bala S, Petrasek J, Mundkur S, Catalano D, Levin I, Ward J, Alao H, Kodys K, Szabo G (2012) Circulating microRNAs in exosomes indicate hepatocyte injury and inflammation in alcoholic, druginduced, and inflammatory liver diseases. Hepatology 56:19461957. https://doi.org/10.1002/hep.25873

Basra S, Anand BS (2011) Definition, epidemiology and magnitude of alcoholic hepatitis. World J Hepatol 3:108-113. https://doi.org/ 10.4254/wjh.v3.i5.108

Bataller R, Brenner DA (2005) Liver fibrosis. J Clin Investig 115:209_ 218. https://doi.org/10.1172/JCI24282

Bernal W, Wendon J (2013) Acute liver failure. N Engl J Med 369:2525-2534. https://doi.org/10.1056/NEJMra1208937

Blanc L, Vidal M (2018) New insights into the function of Rab GTPases in the context of exosomal secretion. Small GTPases 9:95-106. https://doi.org/10.1080/21541248.2016.1264352

Blaner WS, O'Byrne SM, Wongsiriroj N, Kluwe J, D'Ambrosio DM, Jiang H, Schwabe RF, Hillman EM, Piantedosi R, Libien J (2009) Hepatic stellate cell lipid droplets: a specialized lipid droplet for retinoid storage. Biochim Biophys Acta 1791:467-473. https:// doi.org/10.1016/j.bbalip.2008.11.001

Brandon-Warner E, Feilen NA, Culberson CR, Field CO, Delemos AS, Russo MW, Schrum LW (2016) Processing of miR-17-92 cluster in hepatic stellate cells promotes hepatic fibrogenesis during alcohol-induced injury. Alcohol Clin Exp Res 40:1430-1442. https://doi.org/10.1111/acer.13116

Broermann A, Schmid R, Gabrielyan O, Sakowski M, Eisele C, Keller S, Wolff M, Baum P, Stierstorfer B, Huber J, Krämer BK, Hocher B, Streicher R, Delić D (2020) Exosomal miRNAs as potential biomarkers to monitor phosphodiesterase 5 inhibitor induced anti-fibrotic effects on $\mathrm{CCl}_{4}$ treated rats. Int $\mathrm{J}$ Mol Sci 22:382. https://doi.org/10.3390/ijms22010382

Cai P, Mu Y, Olveda RM, Ross AG, Olveda DU, McManus DP (2020) Serum exosomal miRNAs for grading hepatic fibrosis due to schistosomiasis. Int J Mol Sci 21:3560. https://doi.org/10.3390/ ijms 21103560

Castano C, Kalko S, Novials A, Parrizas M (2018) Obesity-associated exosomal miRNAs modulate glucose and lipid metabolism in mice. Proc Natl Acad Sci USA 115:12158-12163. https://doi. org/10.1073/pnas.1808855115

Chen J, Yu Y, Li S, Liu Y, Zhou S, Cao S, Yin J, Li G (2017) MicroRNA-30a ameliorates hepatic fibrosis by inhibiting Beclin1mediated autophagy. J Cell Mol Med 21:3679-3692. https://doi. org/10.1111/jcmm.13278

Chen L, Charrier A, Zhou Y, Chen R, Yu B, Agarwal K, Tsukamoto H, Lee LJ, Paulaitis ME, Brigstock DR (2014) Epigenetic regulation of connective tissue growth factor by microRNA-214 delivery in exosomes from mouse or human hepatic stellate cells. Hepatology 59:1118-1129. https://doi.org/10.1002/hep.26768 
Chen L, Chen R, Kemper S, Charrier A, Brigstock DR (2015) Suppression of fibrogenic signaling in hepatic stellate cells by Twist1-dependent microRNA-214 expression: role of exosmes in horizontal transfer of Twist1. Am J Physiol Gastrointest Liver Physiol 309:G491-499. https://doi.org/10.1152/ajpgi.00140.2015

Chen L, Chen R, Kemper S, Cong M, You H, Brigstock DR (2018) Therapeutic effects of serum extracellular vesicles in liver fibrosis. J Extracell Vesicles 7:1461505. https://doi.org/10.1080/ 20013078.2018.1461505

Chen L, Chen R, Velazquez VM, Brigstock DR (2016) Fibrogenic signaling is suppressed in hepatic stellate cells through targeting of connective tissue growth factor (CCN2) by cellular or exosomal microRNA-199a-5p. Am J Pathol 186:2921-2933. https://doi. org/10.1016/j.ajpath.2016.07.011

Chen L, Yao X, Yao H, Ji Q, Ding G, Liu X (2020) Exosomal miR103-3p from LPS-activated THP-1 macrophage contributes to the activation of hepatic stellate cells. FASEB J 34:5178-5192. https://doi.org/10.1096/fj.201902307RRR

Cocucci E, Meldolesi J (2015) Ectosomes and exosomes: shedding the confusion between extracellular vesicles. Trends Cell Biol 25:364-372. https://doi.org/10.1016/j.tcb.2015.01.004

Collaborators GBDA (2018) Alcohol use and burden for 195 countries and territories, 1990-2016: a systematic analysis for the Global Burden of Disease Study 2016. Lancet 392:1015-1035. https:// doi.org/10.1016/S0140-6736(18)31310-2

Collaborators GBDC (2020) The global, regional, and national burden of cirrhosis by cause in 195 countries and territories, 1990-2017: a systematic analysis for the Global Burden of Disease Study 2017. Lancet Gastroenterol Hepatol 5:245-266. https://doi.org/ 10.1016/S2468-1253(19)30349-8

Csak T, Bala S, Lippai D, Satishchandran A, Catalano D, Kodys K, Szabo G (2015) microRNA-122 regulates hypoxia-inducible factor-1 and vimentin in hepatocytes and correlates with fibrosis in diet-induced steatohepatitis. Liver Int 35:532-541. https://doi. org/10.1111/liv. 12633

Devhare PB, Sasaki R, Shrivastava S, Di Bisceglie AM, Ray R, Ray RB (2017) Exosome-mediated intercellular communication between hepatitis $\mathrm{C}$ virus-infected hepatocytes and hepatic stellate cells. J Virol 91:e02225-e2316. https://doi.org/10.1128/JVI.02225-16

Doyle LM, Wang MZ (2019) Overview of extracellular vesicles, their origin, composition, purpose, and methods for exosome isolation and analysis. Cells 8:727. https://doi.org/10.3390/cells8070727

Friedman SL, Neuschwander-Tetri BA, Rinella M, Sanyal AJ (2018) Mechanisms of NAFLD development and therapeutic strategies. Nat Med 24:908-922. https://doi.org/10.1038/ s41591-018-0104-9

Fründt T, Krause L, Hussey E, Steinbach B, Köhler D, von Felden J, Schulze K, Lohse AW, Wege H, Schwarzenbach H (2021) Diagnostic and prognostic value of miR-16, miR-146a, miR-192 and miR-221 in exosomes of hepatocellular carcinoma and liver cirrhosis patients. Cancers 13:2484. https://doi.org/10.3390/cance rs 13102484

Futter CE, Pearse A, Hewlett LJ, Hopkins CR (1996) Multivesicular endosomes containing internalized EGF-EGF receptor complexes mature and then fuse directly with lysosomes. J Cell Biol 132:1011-1023. https://doi.org/10.1083/jcb.132.6.1011

Gjorgjieva M, Sobolewski C, Dolicka D, Correia De Sousa M, Foti M (2019) miRNAs and NAFLD: from pathophysiology to therapy. Gut 68:2065-2079. https://doi.org/10.1136/gutjnl-2018-318146

Guerra F, Bucci C (2016) Multiple roles of the small GTPase Rab7. Cells 5:34. https://doi.org/10.3390/cells5030034

Ha M, Kim VN (2014) Regulation of microRNA biogenesis. Nat Rev Mol Cell Biol 15:509-524. https://doi.org/10.1038/nrm3838

He Y, Rodrigues RM, Wang X, Seo W, Ma J, Hwang S, Fu Y, Trojnar E, Matyas C, Zhao S, Ren R, Feng D, Pacher P, Kunos G, Gao B (2020) Neutrophil-to-hepatocyte communication via
LDLR-dependent miR-223-enriched extracellular vesicle transfer ameliorates nonalcoholic steatohepatitis. J Clin Investig. https:// doi.org/10.1172/jci141513

Heo MJ, Yun J, Kim SG (2019) Role of non-coding RNAs in liver disease progression to hepatocellular carcinoma. Arch Pharmacal Res 42:48-62. https://doi.org/10.1007/s12272-018-01104-x

Hessvik NP, Llorente A (2018) Current knowledge on exosome biogenesis and release. Cell Mol Life Sci 75:193-208. https://doi. org/10.1007/s00018-017-2595-9

Heydtmann M (2009) Macrophages in hepatitis B and hepatitis C virus infections. J Virol 83:2796-2802. https://doi.org/10.1128/JVI. 00996-08

Holman NS, Church RJ, Nautiyal M, Rose KA, Thacker SE, Otieno MA, Wolf KK, Lecluyse E, Watkins PB, Mosedale M (2019) Hepatocyte-derived exosomes promote liver immune tolerance: possible implications for idiosyncratic drug-induced liver injury. Toxicol Sci 170:499-508. https://doi.org/10.1093/toxsci/kfz112

Hou X, Yin S, Ren R, Liu S, Yong L, Liu Y, Li Y, Zheng MH, Kunos G, Gao B, Wang H (2020) Myeloid cell-specific IL-6 signaling promotes miR-223-enriched exosome production to attenuate NAFLD-associated fibrosis. Hepatology. https://doi.org/10. 1002/hep.31658

Hsu C, Morohashi Y, Yoshimura S, Manrique-Hoyos N, Jung S, Lauterbach MA, Bakhti M, Grønborg M, Möbius W, Rhee J, Barr FA, Simons M (2010) Regulation of exosome secretion by Rab35 and its GTPase-activating proteins TBC1D10A-C. J Cell Biol 189:223-232. https://doi.org/10.1083/jcb.200911018

Huotari J, Helenius A (2011) Endosome maturation. EMBO J 30:34813500. https://doi.org/10.1038/emboj.2011.286

Ioannou GN (2016) The role of cholesterol in the pathogenesis of NASH. Trends Endocrinol Metab 27:84-95. https://doi.org/10. 1016/j.tem.2015.11.008

Josephs MD, Bahjat FR, Fukuzuka K, Ksontini R, Solorzano CC, Edwards CK III, Tannahill CL, Mackay SL, Copeland EM III, Moldawer LL (2000) Lipopolysaccharide and D-galactosamineinduced hepatic injury is mediated by TNF-alpha and not by Fas ligand. Am J Physiol 278:R1196-1201. https://doi.org/10.1152/ ajpregu.2000.278.5.R1196

Kariba Y, Yoshizawa T, Sato Y, Tsuyama T, Araki E, Yamagata K (2020) Brown adipocyte-derived exosomal miR-132-3p suppress hepatic Srebf1 expression and thereby attenuate expression of lipogenic genes. Biochem Biophys Res Commun 530:500-507. https://doi.org/10.1016/j.bbrc.2020.05.090

Kim JH, Lee CH, Lee SW (2019) Exosomal transmission of microRNA from HCV replicating cells stimulates transdifferentiation in hepatic stellate cells. Mol Ther Nucleic Acids 14:483-497. https://doi.org/10.1016/j.omtn.2019.01.006

Kim KM, Han CY, Kim JY, Cho SS, Kim YS, Koo JH, Lee JM, Lim SC, Kang KW, Kim JS, Hwang SJ, Ki SH, Kim SG (2018) Galpha12 overexpression induced by miR-16 dysregulation contributes to liver fibrosis by promoting autophagy in hepatic stellate cells. J Hepatol 68:493-504. https://doi.org/10.1016/j.jhep.2017. 10.011

Komatsu S, Ichikawa D, Takeshita H, Morimura R, Hirajima S, Tsujiura M, Kawaguchi T, Miyamae M, Nagata H, Konishi H, Shiozaki A, Otsuji E (2014) Circulating miR-18a: a sensitive cancer screening biomarker in human cancer. In Vivo 28:293-297

Kong L, Zhou Y, Bu H, Lv T, Shi Y, Yang J (2016) Deletion of interleukin-6 in monocytes/macrophages suppresses the initiation of hepatocellular carcinoma in mice. J Exp Clin Cancer Res 35:131. https://doi.org/10.1186/s13046-016-0412-1

Koo JH, Lee HJ, Kim W, Kim SG (2016) Endoplasmic reticulum stress in hepatic stellate cells promotes liver fibrosis via PERK-mediated degradation of HNRNPA1 and up-regulation of SMAD2. Gastroenterology 150:181-193.e188. https://doi.org/10.1053/j. gastro.2015.09.039 
Lee J, Park JS, Roh YS (2019) Molecular insights into the role of mitochondria in non-alcoholic fatty liver disease. Arch Pharmacal Res 42:935-946. https://doi.org/10.1007/s12272-019-01178-1

Lee YS, Kim SY, Ko E, Lee JH, Yi HS, Yoo YJ, Je J, Suh SJ, Jung YK, Kim JH, Seo YS, Yim HJ, Jeong WI, Yeon JE, Um SH, Byun KS (2017) Exosomes derived from palmitic acid-treated hepatocytes induce fibrotic activation of hepatic stellate cells. Sci Rep 7:3710. https://doi.org/10.1038/s41598-017-03389-2

Li D, Song H, Shuo L, Wang L, Xie P, Li W, Liu J, Tong Y, Zhang CY, Jiang X, Li J, Zhang Y (2020a) Gonadal white adipose tissuederived exosomal miR-222 promotes obesity-associated insulin resistance. Aging (Albany NY) 12:22719-22743. https://doi.org/ 10.18632/aging.103891

Li Y, Luan Y, Li J, Song H, Li Y, Qi H, Sun B, Zhang P, Wu X, Liu X, Yang Y, Tao W, Cai L, Yang Z, Yang Y (2020b) Exosomal miR-199a-5p promotes hepatic lipid accumulation by modulating MST1 expression and fatty acid metabolism. Hepatol Int 14:1057-1074. https://doi.org/10.1007/s12072-020-10096-0

Liu CH, Ampuero J, Gil-Gómez A, Montero-Vallejo R, Rojas Ã, Muñoz-Hernández R, Gallego-Durán R, Romero-Gómez M (2018a) miRNAs in patients with non-alcoholic fatty liver disease: a systematic review and meta-analysis. J Hepatol 69:13351348. https://doi.org/10.1016/j.jhep.2018.08.008

Liu XL, Pan Q, Cao HX, Xin FZ, Zhao ZH, Yang RX, Zeng J, Zhou H, Fan JG (2020) Lipotoxic hepatocyte-derived exosomal microRNA 192-5p activates macrophages through rictor/Akt/forkhead box transcription factor $\mathrm{O} 1$ signaling in nonalcoholic fatty liver disease. Hepatology 72:454-469. https://doi.org/10.1002/hep. 31050

Liu Y, Lou G, Li A, Zhang T, Qi J, Ye D, Zheng M, Chen Z (2018b) AMSC-derived exosomes alleviate lipopolysaccharide/Dgalactosamine-induced acute liver failure by miR-17-mediated reduction of TXNIP/NLRP3 inflammasome activation in macrophages. EBioMedicine 36:140-150. https://doi.org/10.1016/j. ebiom.2018.08.054

Lou G, Yang Y, Liu F, Ye B, Chen Z, Zheng M, Liu Y (2017) miR-122 modification enhances the therapeutic efficacy of adipose tissuederived mesenchymal stem cells against liver fibrosis. J Cell Mol Med 21:2963-2973. https://doi.org/10.1111/jcmm.13208

Mehal WZ, Azzaroli F, Crispe IN (2001) Immunology of the healthy liver: old questions and new insights. Gastroenterology 120:250 260. https://doi.org/10.1053/gast.2001.20947

Miyaji T, Takami T, Fujisawa K, Matsumoto T, Yamamoto N, Sakaida I (2020) Bone marrow-derived humoral factors suppress oxidative phosphorylation, upregulate TSG-6, and improve therapeutic effects on liver injury of mesenchymal stem cells. J Clin Biochem Nutr 66:213-223. https://doi.org/10.3164/jcbn.19-125

Mogilyansky E, Rigoutsos I (2013) The miR-17/92 cluster: a comprehensive update on its genomics, genetics, functions and increasingly important and numerous roles in health and disease. Cell Death Differ 20:1603-1614. https://doi.org/10.1038/cdd.2013. 125

Möller A, Lobb RJ (2020) The evolving translational potential of small extracellular vesicles in cancer. Nat Rev Cancer 20:697-709. https://doi.org/10.1038/s41568-020-00299-w

Momen-Heravi F, Bala S, Bukong T, Szabo G (2014) Exosomemediated delivery of functionally active miRNA-155 inhibitor to macrophages. Nanomedicine 10:1517-1527. https://doi.org/ 10.1016/j.nano.2014.03.014

Momen-Heravi F, Bala S, Kodys K, Szabo G (2015a) Exosomes derived from alcohol-treated hepatocytes horizontally transfer liver specific miRNA-122 and sensitize monocytes to LPS. Sci Rep 5:9991. https://doi.org/10.1038/srep09991

Momen-Heravi F, Saha B, Kodys K, Catalano D, Satishchandran A, Szabo G (2015b) Increased number of circulating exosomes and their microRNA cargos are potential novel biomarkers in alcoholic hepatitis. J Transl Med 13:261. https://doi.org/10.1186/ s12967-015-0623-9

Motawi TK, Mohamed MR, Shahin NN, MaM A, Azzam MA (2018) Time-course expression profile and diagnostic potential of a miRNA panel in exosomes and total serum in acute liver injury. Int J Biochem Cell Biol 100:11-21. https://doi.org/10.1016/j. biocel.2018.05.002

Mulcahy LA, Pink RC, Carter DR (2014) Routes and mechanisms of extracellular vesicle uptake. J Extracell Vesicles 3:24641. https:// doi.org/10.3402/jev.v3.24641

Niu LJ, Zhang YM, Huang T, Sun XF, Luo SX (2021) Exosomal microRNA-155 as a biomarker for hepatic fibrosis diagnosis and progression. Ann Transl Med 9:137. https://doi.org/10.21037/ atm-20-7787

Novellino L, Rossi RL, Bonino F, Cavallone D, Abrignani S, Pagani M, Brunetto MR (2012) Circulating hepatitis B surface antigen particles carry hepatocellular microRNAs. PLoS ONE 7:e31952. https://doi.org/10.1371/journal.pone.0031952

Ostrowski M, Carmo NB, Krumeich S, Fanget I, Raposo G, Savina A, Moita CF, Schauer K, Hume AN, Freitas RP, Goud B, Benaroch P, Hacohen N, Fukuda M, Desnos C, Seabra MC, Darchen F, Amigorena S, Moita LF, Thery C (2010) Rab27a and Rab27b control different steps of the exosome secretion pathway. Nat Cell Biol 12:19-30. https://doi.org/10.1038/ncb2000

Pan JH, Zhou H, Zhao XX, Ding H, Li W, Qin L, Pan YL (2018) Role of exosomes and exosomal microRNAs in hepatocellular carcinoma: potential in diagnosis and antitumour treatments (Review). Int J Mol Med 41:1809-1816. https://doi.org/10.3892/ ijmm.2018.3383

Parekkadan B, Milwid JM (2010) Mesenchymal stem cells as therapeutics. Ann Rev Biomed Eng 12:87-117. https://doi.org/10.1146/ annurev-bioeng-070909-105309

Povero D, Eguchi A, Li H, Johnson CD, Papouchado BG, Wree A, Messer K, Feldstein AE (2014) Circulating extracellular vesicles with specific proteome and liver microRNAs are potential biomarkers for liver injury in experimental fatty liver disease. PLoS ONE 9:e113651. https://doi.org/10.1371/journal.pone.0113651

Prada I, Meldolesi J (2016) Binding and fusion of extracellular vesicles to the plasma membrane of their cell targets. Int J Mol Sci 17:1296. https://doi.org/10.3390/ijms17081296

Rachfal AW, Brigstock DR (2003) Connective tissue growth factor (CTGF/CCN2) in hepatic fibrosis. Hepatol Res 26:1-9. https:// doi.org/10.1016/s1386-6346(03)00115-3

Raposo G, Stoorvogel W (2013) Extracellular vesicles: exosomes, microvesicles, and friends. J Cell Biol 200:373-383. https://doi. org/10.1083/jcb.201211138

Saha B, Momen-Heravi F, Kodys K, Szabo G (2016) MicroRNA cargo of extracellular vesicles from alcohol-exposed monocytes signals naive monocytes to differentiate into M2 macrophages. J Biol Chem 291:149-159. https://doi.org/10.1074/jbc.M115.694133

Sato K, Meng F, Glaser S, Alpini G (2016) Exosomes in liver pathology. J Hepatol 65:213-221. https://doi.org/10.1016/j.jhep.2016. 03.004

Savina A, Vidal M, Colombo MI (2002) The exosome pathway in K562 cells is regulated by Rab11. J Cell Sci 115:2505-2515. https:// doi.org/10.1242/jcs.115.12.2505

Schmidt-Arras D, Rose-John S (2016) IL-6 pathway in the liver: from physiopathology to therapy. J Hepatol 64:1403-1415. https://doi. org/10.1016/j.jhep.2016.02.004

Shao M, Xu Q, Wu Z, Chen Y, Shu Y, Cao X, Chen M, Zhang B, Zhou Y, Yao R, Shi Y, Bu H (2020) Exosomes derived from human umbilical cord mesenchymal stem cells ameliorate IL6-induced acute liver injury through miR-455-3p. Stem Cell Res Ther 11:37. https://doi.org/10.1186/s13287-020-1550-0

Song P, Trajkovic K, Tsunemi T, Krainc D (2016) Parkin modulates endosomal organization and function of the endo-lysosomal 
pathway. J Neurosci 36:2425-2437. https://doi.org/10.1523/jneur osci.2569-15.2016

Szabo G, Momen-Heravi F (2017) Extracellular vesicles in liver disease and potential as biomarkers and therapeutic targets. Nat Rev Gastroenterol Hepatol 14:455-466. https://doi.org/10.1038/nrgas tro.2017.71

Tamura R, Uemoto S, Tabata Y (2016) Immunosuppressive effect of mesenchymal stem cell-derived exosomes on a concanavalin A-induced liver injury model. Inflamm Regen 36:26. https://doi. org/10.1186/s41232-016-0030-5

Taylor RS, Taylor RJ, Bayliss S, Hagstrom H, Nasr P, Schattenberg JM, Ishigami M, Toyoda H, Wai-Sun Wong V, Peleg N, Shlomai A, Sebastiani G, Seko Y, Bhala N, Younossi ZM, Anstee QM, Mcpherson S, Newsome PN (2020) Association between fibrosis stage and outcomes of patients with nonalcoholic fatty liver disease: a systematic review and meta-analysis. Gastroenterology 158:1611-1625.e1612. https://doi.org/10.1053/j.gastro. 2020.01 .043

Teschke R (2019) Idiosyncratic DILI: analysis of 46,266 cases assessed for causality by RUCAM and published from 2014 to early 2019 . Front Pharmacol 10:730. https://doi.org/10.3389/fphar.2019. 00730

Thomou T, Mori MA, Dreyfuss JM, Konishi M, Sakaguchi M, Wolfrum C, Rao TN, Winnay JN, Garcia-Martin R, Grinspoon SK, Gorden P, Kahn CR (2017) Adipose-derived circulating miRNAs regulate gene expression in other tissues. Nature 542:450-455. https://doi.org/10.1038/nature21365

Treiber T, Treiber N, Meister G (2019) Regulation of microRNA biogenesis and its crosstalk with other cellular pathways. Nat Rev Mol Cell Biol 20:5-20. https://doi.org/10.1038/ s41580-018-0059-1

Turchinovich A, Drapkina O, Tonevitsky A (2019) Transcriptome of extracellular vesicles: state-of-the-art. Front Immunol 10:202. https://doi.org/10.3389/fimmu.2019.00202

Uetrecht J (2019) Mechanistic studies of idiosyncratic DILI: clinical implications. Front Pharmacol 10:837. https://doi.org/10.3389/ fphar.2019.00837

Ullah I, Subbarao RB, Rho GJ (2015) Human mesenchymal stem cells-current trends and future prospective. Biosci Rep 35:e00191. https://doi.org/10.1042/bsr20150025

Urban SK, Mocan T, Sänger H, Lukacs-Kornek V, Kornek M (2019) Extracellular vesicles in liver diseases: diagnostic, prognostic, and therapeutic application. Semin Liver Dis 39:70-77. https:// doi.org/10.1055/s-0038-1676122

Van Niel G, D'Angelo G, Raposo G (2018) Shedding light on the cell biology of extracellular vesicles. Nat Rev Mol Cell Biol 19:213228. https://doi.org/10.1038/nrm.2017.125

Vanlandingham PA, Ceresa BP (2009) Rab7 regulates late endocytic trafficking downstream of multivesicular body biogenesis and cargo sequestration. J Biol Chem 284:12110-12124. https://doi. org/10.1074/jbc.M809277200

Villarroya-Beltri C, Gutiérrez-Vázquez C, Sánchez-Cabo F, PérezHernández D, Vázquez J, Martin-Cofreces N, Martinez-Herrera DJ, Pascual-Montano A, Mittelbrunn M, Sánchez-Madrid F (2013) Sumoylated hnRNPA2B1 controls the sorting of miRNAs into exosomes through binding to specific motifs. Nat Commun 4:2980. https://doi.org/10.1038/ncomms3980

Wang M, Yuan Q, Xie L (2018) Mesenchymal stem cell-based immunomodulation: properties and clinical application. Stem Cell Int 2018:3057624. https://doi.org/10.1155/2018/3057624

Wang S, Luan J, Lv X (2019) Inhibition of endoplasmic reticulum stress attenuated ethanol-induced exosomal miR-122 and acute liver injury in mice. Alcohol Alcohol 54:465-471. https://doi. org/10.1093/alcalc/agz058

Weigand K, Brost S, Steinebrunner N, Büchler M, Schemmer P, Müller M (2012) Ischemia/reperfusion injury in liver surgery and transplantation: pathophysiology. HPB Surg 2012:176723. https://doi.org/10.1155/2012/176723

Wu J, Dong T, Chen T, Sun J, Luo J, He J, Wei L, Zeng B, Zhang H, Li W, Liu J, Chen X, Su M, Ni Y, Jiang Q, Zhang Y, Xi Q (2020) Hepatic exosome-derived miR-130a-3p attenuates glucose intolerance via suppressing PHLPP2 gene in adipocyte. Metabolism 103:154006. https://doi.org/10.1016/j.metabol. 2019.154006

Xie K, Liu L, Chen J, Liu F (2019a) Exosomal miR-1246 derived from human umbilical cord blood mesenchymal stem cells attenuates hepatic ischemia reperfusion injury by modulating T helper 17/ regulatory T balance. IUBMB Life 71:2020-2030. https://doi. org/10.1002/iub.2147

Xie K, Liu L, Chen J, Liu F (2019b) Exosomes derived from human umbilical cord blood mesenchymal stem cells improve hepatic ischemia reperfusion injury via delivering miR-1246. Cell Cycle 18:3491-3501. https://doi.org/10.1080/15384101.2019.1689480

Yamashita YI, Imai K, Mima K, Nakagawa S, Hashimoto D, Chikamoto A, Baba H (2017) Idiosyncratic drug-induced liver injury: a short review. Hepatol Commun 1:494-500. https://doi.org/10. 1002/hep4.1064

Yang L, Miura K, Zhang B, Matsushita H, Yang YM, Liang S, Song J, Roh YS, Seki E (2017a) TRIF differentially regulates hepatic steatosis and inflammation/fibrosis in mice. Cell Mol Gastroenterol Hepatol 3:469-483. https://doi.org/10.1016/j.jcmgh.2016.12.004

Yang X, Li H, Sun H, Fan H, Hu Y, Liu M, Li X, Tang H (2017b) Hepatitis B virus-encoded microRNA controls viral replication. J Virol. https://doi.org/10.1128/JVI.01919-16

Yang YM, Lee WH, Lee CG, An J, Kim ES, Kim SH, Lee SK, Lee CH, Dhanasekaran DN, Moon A, Hwang S, Lee SJ, Park JW, Kim KM, Kim SG (2015) Galpha12 gep oncogene deregulation of p53-responsive microRNAs promotes epithelial-mesenchymal transition of hepatocellular carcinoma. Oncogene 34:2910-2921. https://doi.org/10.1038/onc.2014.218

Yang YM, Noureddin M, Liu C, Ohashi K, Kim SY, Ramnath D, Powell EE, Sweet MJ, Roh YS, Hsin IF, Deng N, Liu Z, Liang J, Mena E, Shouhed D, Schwabe RF, Jiang D, Lu SC, Noble PW, Seki E (2019) Hyaluronan synthase 2-mediated hyaluronan production mediates Notch1 activation and liver fibrosis. Sci Transl Med 11:eaat9284. https://doi.org/10.1126/scitranslmed.aat9284

Yang YM, Seo SY, Kim TH, Kim SG (2012) Decrease of microRNA-122 causes hepatic insulin resistance by inducing protein tyrosine phosphatase $1 \mathrm{~B}$, which is reversed by licorice flavonoid. Hepatology 56:2209-2220. https://doi.org/10.1002/hep.25912

Yang YM, Wang Z, Matsuda M, Seki E (2021) Inhibition of hyaluronan synthesis by 4-methylumbelliferone ameliorates non-alcoholic steatohepatitis in choline-deficient L-amino acid-defined dietinduced murine model. Arch Pharmacal Res 44:230-240. https:// doi.org/10.1007/s12272-021-01309-7

Ye D, Zhang T, Lou G, Liu Y (2018) Role of miR-223 in the pathophysiology of liver diseases. Exp Mol Med 50:128. https://doi. org/10.1038/s12276-018-0153-7

Ying W, Riopel M, Bandyopadhyay G, Dong Y, Birmingham A, Seo JB, Ofrecio JM, Wollam J, Hernandez-Carretero A, Fu W, Li P, Olefsky JM (2017) Adipose tissue macrophage-derived exosomal miRNAs can modulate in vivo and in vitro insulin sensitivity. Cell 171:372-384.e312. https://doi.org/10.1016/j.cell.2017.08. 035

Zhang L, Song Y, Chen L, Li D, Feng H, Lu Z, Fan T, Chen Z, Livingston MJ, Geng Q (2020a) miR-20a-containing exosomes from umbilical cord mesenchymal stem cells alleviates liver ischemia/ reperfusion injury. J Cell Physiol 235:3698-3710. https://doi.org/ $10.1002 /$ jcp. 29264

Zhang S, Jiang L, Hu H, Wang H, Wang X, Jiang J, Ma Y, Yang J, Hou Y, Xie D, Zhang Q (2020b) Pretreatment of exosomes derived from hUCMSCs with TNF- $\alpha$ ameliorates acute liver failure by 
inhibiting the activation of NLRP3 in macrophage. Life Sci 246:117401. https://doi.org/10.1016/j.lfs.2020.117401

Zhang Y, Liu Y, Liu H, Tang WH (2019) Exosomes: biogenesis, biologic function and clinical potential. Cell Biosci 9:19. https://doi. org/10.1186/s13578-019-0282-2

Zhang Y, Wang D, Shen D, Luo Y, Che YQ (2020c) Identification of exosomal miRNAs associated with the anthracycline-induced liver injury in postoperative breast cancer patients by small RNA sequencing. PeerJ 8:e9021. https://doi.org/10.7717/peerj.9021

Zhao X, Sun L, Mu T, Yi J, Ma C, Xie H, Liu M, Tang H (2020a) An HBV-encoded miRNA activates innate immunity to restrict HBV replication. J Mol Cell Biol 12:263-276. https://doi.org/10.1093/ jmcb/mjz104

Zhao Z, Zhong L, Li P, He K, Qiu C, Zhao L, Gong J (2020b) Cholesterol impairs hepatocyte lysosomal function causing M1 polarization of macrophages via exosomal miR-122-5p. Exp Cell Res 387:111738. https://doi.org/10.1016/j.yexcr.2019.111738

Zhou Y, Wang X, Sun L, Zhou L, Ma TC, Song L, Wu JG, Li JL, Ho WZ (2016) Toll-like receptor 3-activated macrophages confer anti-HCV activity to hepatocytes through exosomes. FASEB J 30:4132-4140. https://doi.org/10.1096/fj.201600696R

Publisher's Note Springer Nature remains neutral with regard to jurisdictional claims in published maps and institutional affiliations. 